\title{
Um Estudo Exploratório do Controle Gerencial de Ativos e Recursos Intangíveis em Empresas Brasileiras
}

\author{
José Geraldo P. Barbosa \\ Josir Simeone Gomes
}

\section{Resumo}

O objetivo desta pesquisa foi avaliar, em três empresas brasileiras do setor de serviços, a importância atribuída por elas a seus ativos/recursos intangíveis. A importância atribuída a cada ativo/recurso intangível foi verificada por meio do seguinte elenco aferido: (1) utilização de um método que procurava medir, em cada empresa, a presença de diversos fatores constituintes de cada ativo/ recurso intangível; (2) associação de cada ativo/recurso a ações gerenciais de intervenção consideradas relevantes; e, finalmente, (3) sua associação a indicadores e/ou índices de desempenho freqüentemente utilizados. Estes três critérios de importância foram preenchidos a partir da análise sistematizada de entrevistas concedidas por membros da alta direção de cada empresa. A pesquisa conduzida permitiu três derivações: (1) verificar a aplicação prática de conceitos de gerenciamento de ativos/recursos intangíveis constantes da literatura; (2) tecer algumas conclusões importantes sobre a origem dos diferentes graus de importância atribuídos a cada ativo/recurso intangível; e, finalmente, (3) sugerir , no futuro, a condução de dois estudos exploratórios e de um levantamento.

Palavras-chaves: controle gerencial; capital intelectual; medição.

\section{Abstract}

This study has for objective to evaluate, in three brazilian companies of the services sector, the importance granted by them to their intangible assets. For the purpose of this study, the body of intangible assets of a company is defined as composed of the technical competence of its workforce; its ability to transfer and incorporate knowledge; the quality level of its relationship with customers, suppliers and job market; and the intensity of its research and development effort. The importance of each intangible asset is verified by (1) the degree of presence of components of each asset; (2) the number of relevant managerial activities related to each asset; and finally (3) the number of frequently used performance indicators related to each intangible asset.

Key words: management; intellectual capital; measurement. 


\section{INTRODUÇÃO}

Este estudo busca verificar o grau de importância concedido por empresas brasileiras selecionadas aos seus diversos ativos/recursos intangíveis. Para o atendimento deste objetivo se faz necessário, de acordo com a percepção própria de cada empresa, identificar e qualificar seus ativos e recursos intangíveis; relacionálos aos indicadores e índices de desempenho mais freqüentemente utilizados; relacioná-los às ações gerenciais de intervenção consideradas relevantes; e analisar os dispêndios associados aos ativos/recursos intangíveis.

Para os propósitos deste estudo, entende-se como conjunto de ativos/recursos intangíveis de uma empresa o conjunto formado por:

. Conhecimento Acadêmico e Tácito de seus Funcionários (C).

. seus Processos Facilitadores de Transferência e Aquisição de Conhecimento (T).

. seu Relacionamento com Clientes, Fornecedores e Mercado de Trabalho (R).

. sua Capacitação em Pesquisa e Desenvolvimento (P).

A este conjunto de ativos/recursos costuma-se atribuir os nomes knowledgebased assets e capital intelectual, sendo que esta última forma parece estar ganhando mais espaço, tanto nos círculos acadêmicos e empresariais, quanto na mídia. Incorporado nos ativos/recursos intangíveis está o fator conhecimento, causa principal de sua intangibilidade e valor.

Pode-se perceber que este conjunto de ativos/recursos, denominado capital intelectual, está a exigir nova abordagem de controle gerencial, que seja pautada principalmente pela utilização de indicadores e índices não financeiros. É esta nova abordagem de controle gerencial que será objeto da presente pesquisa.

\section{Referencial Teórico}

Um controle gerencial adequado do capital intelectual parte da hipótese de que os ativos e recursos básicos disponíveis para uma empresa, sejam eles pes- 
soas, processos organizacionais e produtivos, tecnologias adotadas, insumos etc., somente serão relevantes para a empresa se ela puder, de forma eficiente e eficaz, utilizar o conhecimento neles incorporado. O não reconhecimento contábil do valor financeiro da parcela intangível destes ativos e recursos teria sido, na opinião de Edvinson e Malone (1997), a causa das grandes discrepâncias existentes entre os preços finais pelos quais algumas empresas foram adquiridas, no grande processo de fusões e aquisições ocorrido principalmente nos Estados Unidos na década passada, e seus valores declarados em balanços patrimoniais publicados. Da mesma forma, Sveiby (1997) chama a atenção para a discrepância entre os preços das empresas, calculados em função dos preços de suas ações em bolsas de valores, e aqueles declarados em balanços publicados.

\section{Classificando o Capital Intelectual}

A argumentação desta seção basear-se-á fundamentalmente nas idéias de Edvinsson e Malone (1997) e Sveiby (1997). Estes autores abordam a questão de controle gerencial de ativos/recursos intangíveis, a partir do reconhecimento da importância do conhecimento neles incorporado. São similares também suas opiniões sobre a maior eficiência dos indicadores e índices não financeiros utilizados na medição de ativos/recursos intangíveis, quando comparados com os financeiros, para a avaliação da real saúde da empresa, bem como para a previsão de cenários futuros.

Iniciemos com Sveiby (1997). Este autor afirma que os ativos/recursos intangíveis de uma empresa seriam compostos pelo conjunto de competências dos seus indivíduos membros, pela sua estrutura interna, utilizada como fio condutor de conhecimento dentro dela, e finalmente pela sua estrutura externa, servindo como fio condutor de conhecimento entre ela e seus clientes e fornecedores. Como competência individual, ele define o conhecimento explícito, o conhecimento tácito, a experiência, o julgamento de valor e a socialização passada de que é possuidor cada indivíduo.

Na opinião de Sveiby (1997), o segundo grupo de ativos/recursos intangíveis seria a estrutura interna da empresa, utilizada como fio condutor de conhecimento dentro dela. Esta estrutura, com cargos ocupados basicamente por gerentes e pessoal de suporte operacional/administrativo, seria projetada para atender três grandes tarefas: o gerenciamento das tensões entre os profissionais (funcionários especializados) e os gerentes; o gerenciamento dos processos de prestação de serviços e/ou produção; e a transferência de conhecimento tácito.

Como terceiro grupo de ativos/recursos intangíveis viria a estrutura externa da empresa, responsável pelo seu relacionamento com seus clientes, fornecedo- 
res e o mercado de trabalho. A estrutura externa, mais do que gerir o fluxo financeiro entre os seus diversos atores, se encarregaria do tráfego de competências, conhecimento, referências favoráveis, imagem da empresa etc. Uma adequada estrutura externa obteria, em seu relacionamento com os clientes, benefícios intangíveis superiores aos financeiros.

Passamos agora a relatar a classificação de ativos/recursos intangíveis proposta por Edvinsson e Malone (1997). Como mencionado anteriormente, Sveiby (1997) é bastante contundente ao declarar o conhecimento como fonte principal de valorização dos ativos e recursos de uma empresa. Esta veemência parece não ocorrer com Edvinsson e Malone (1997), apesar de se verificar a presença do conhecimento como pano de fundo em toda a sua argumentação.

Os autores recorrem a uma metáfora para melhor exemplificar a intangibilidade de certos ativos e recursos de uma empresa. Assim, eles comparam a empresa a uma árvore, cujo tronco, ramos, folhas e frutos seriam os representantes dos ativos e recursos tangíveis, enquanto os intangíveis (invisíveis) seriam representados por suas raízes que, na maioria das vezes, correspondem a mais da metade da massa da árvore. Embora uma análise de seus frutos e folhas possa nos dar uma boa idéia da saúde presente da árvore, somente uma investigação de suas raízes é que nos daria uma idéia da sua saúde futura.

Segundo Edvinsson e Malone (1997), os ativos e recursos intangíveis poderiam ser agrupados em relacionamento com clientes, conjunto de processos produtivos e de prestação de serviços, capacidade de renovação e desenvolvimento (R\&D) e capital humano.

Por relacionamento com clientes se entende principalmente a qualidade deste relacionamento, traduzida aqui como a capacidade de a empresa se antecipar na previsão das necessidades de seus clientes e, com isto, canalizar sua demanda.

O segundo grupo de ativos e recursos intangíveis seria formado pelo conjunto de processos produtivos e de prestação de serviços da empresa.

Como terceiro grupo de ativos e recursos intangíveis viria a capacidade de renovação e desenvolvimento (R\&D) da empresa, representada pelas adaptações, no presente, às oportunidades que somente aparecerão no futuro próximo, ou motivadas, sem aviso prévio, por alterações radicais no comportamento do mercado. Este grupo de ativos/recursos intangíveis seria um dos pilares do crescimento sustentável da empresa. Seis atividades deveriam ser continuamente conduzidas pela empresa, se ela deseja manter elevada a sua capacidade de renovação: (1) busca de conhecimento permanente sobre as tendências dos clientes; (2) procura incessante por novas oportunidades de negócios oferecidas no mercado; (3) investimento em desenvolvi- 
mento de novos produtos e serviços; (4) busca de intensas parcerias comerciais; (5) investimento em novas ferramentas de suporte organizacional; (6) finalmente, o investimento no desenvolvimento de competências dos funcionários.

Finalmente, chegaríamos ao quarto e último grupo de ativos/recursos intangíveis, aquele composto pelas competências dos membros individuais da empresa. São eles os responsáveis pela integração e alinhamento comum dos demais ativos e recursos, intangíveis ou não.

\section{Indicadores e Índices Não Financeiros}

Existe dois tipos de indicadores e índices: aqueles que medem eficiência e aqueles que medem eficácia. Os indicadores e índices de eficiência determinam basicamente a relação insumos/serviço ou produto, em termos físicos ou financeiros. Aos indicadores e índices de eficácia caberia determinar se o serviço ou produto, gerado de forma eficiente ou não, estaria atendendo às necessidades do cliente. Indicadores e índices de eficácia são mais difíceis de serem implementados, porque eles exigem um olhar para fora da empresa, ou seja, exigem contatos mais estreitos com clientes, fornecedores e mercado de trabalho.

Sveiby (1997) também recomenda que, para cada grupo de ativos e recursos, sejam escolhidos indicadores e índices representativos da eficiência, da capacidade de renovação e desenvolvimento $(R \& D)$ e da estabilidade de cada grupo. Enquanto os indicadores e índices de eficiência fornecem um quadro da presente saúde da empresa, os de renovação e desenvolvimento (R\&D) olham para o futuro imediato e para o crescimento sustentável, estabelecendo o que a empresa deve fazer agora para abocanhar as oportunidades futuras.

Com relação aos indicadores e índices financeiros tradicionais, Kaplan e Norton (1997) argumentam que eles não traduzem, por exemplo, a satisfação do cliente, a qualidade do serviço, a motivação do funcionário etc. e, portanto, não podem ser utilizados para produzir variações em importantes ativos e recursos intangíveis. O sucesso ou fracasso financeiro, traduzido por estes indicadores e índices financeiros, seria meramente uma conseqüência de ações gerenciais em ativos/ recursos intangíveis, guiadas por indicadores e índices não financeiros.

\section{Concordâncias e Divergências de um Controle Gerencial Adequado ao Capital Intelectual com Abordagens Clássicas de Controle Gerencial}

Esta seção pretende encontrar em abordagens clássicas de controle gerencial, vigentes no início da década de 80, as possíveis fontes de inspiração para os 
acadêmicos e empresários de origem nórdica, responsáveis pelo aumento de interesse, durante a segunda metade da década de 80 e início da década de 90, por pesquisas e práticas relativas a ativos/recursos intangíveis e a seu controle gerencial. Para esta finalidade será utilizada a tese de doutorado de Gomes (1983) que apresenta, de forma sucinta, as principais abordagens do controle gerencial, vigentes no início da década de 80, quais sejam aquelas de Anthony, de Lorange e Morton, de Hofstede e de Flamholt (apud Gomes, 1983).

Mais do que classificações e níveis de decisões, Lorange e Morton (apud Gomes, 1983) preferem salientar o caráter orgânico do controle gerencial, em função da sua necessidade de adaptações e conformações a imposições ambientais externas e internas. Outra concordância também aparece, quando os autores enfatizam a utilização de indicadores e índices não financeiros, já que, para eles, os indicadores e índices financeiros seriam insuficientes para previsão de cenários empresariais inseridos em ambientes instáveis.

Em Hofstede (apud Gomes, 1983), nota-se uma nítida preocupação do autor com o nível das tensões que surgem entre gerentes e profissionais, alocadas numa mesma atividade; com a possibilidade de se encontrar indicadores e índices que meçam os efeitos das ações gerenciais de intervenção; assim como com o efeito benéfico da repetitividade da atividade sobre o aprendizado e, conseqüentemente, o aumento do conhecimento da empresa. As tensões acima mencionadas derivariam de um conflito de interesses entre os participantes (profissionais e gerentes) da atividade, de uma falta de conhecimento da relação meio-fim e de turbulências ambientais, tudo isso gerando objetivos ambíguos para a atividade. Para a eliminação de ambigüidades, sugere Hofstede (apud Gomes, 1983), entre outras medidas, um intenso processo de negociação entre os participantes, assim como a utilização de profissionais e/ou consultores para geração de maior conhecimento da relação da atividade (meio) com sua finalidade.

\section{Metodologia}

A pesquisa tem por objetivo responder às seguintes perguntas:

. Quais ativos/recursos intangíveis são valorizados em empresas brasileiras selecionadas?

. Estão eles associados a índices e/ou indicadores de desempenho, freqüentemente consultados? 
. Estão eles associados a ações gerenciais de intervenção, consideradas relevantes, nestas empresas?

Buscando responder a estas perguntas, os quatro grupos de ativos/recursos intangíveis, o elenco de ações gerenciais praticadas, o sistema de medição de desempenho (indicadores e índices) e os dispêndios associados a ativos/recursos intangíveis, foram transformados em variáveis da pesquisa. Estas variáveis foram, então, identificadas e/ou qualificadas, em cada uma das empresas selecionadas.

\section{O Método de Coleta de Dados}

Na coleta de dados visando à identificação das variáveis da pesquisa, foram utilizados questionários que contêm, em sua maioria, questões abertas e tabelas. As questões e tabelas tinham como finalidade explorar, ora em termos de verificação de existência, ora mediante análise, ora por meio do processo de evolução, os itens constituintes de cada variável da pesquisa.

Com relação às ações gerenciais (relevantes) de intervenção, aos indicadores e índices de desempenho freqüentemente utilizados, e aos dispêndios associados a ativos/recursos intangíveis, foi solicitado a cada entrevistado que os listassem em tabelas apropriadas, entregues durante a entrevista, e que elas fossem devolvidas num prazo de 2 semanas após a entrevista.

Foram solicitados a cada empresa os dispêndios, ocorridos no exercício de 1999, relacionados a:

. Treinamento profissional de funcionários.

- Pesquisas de opinião.

. Formação acadêmica de funcionários.

. Pesquisas de mercado.

- Aquisição de revistas, livros e publicações técnicas.

. Eventos de socialização dos funcionários da empresa com clientes/fornecedores.

. Participação de funcionários em congressos, feiras e seminários.

. Publicidade.

. Eventos de socialização entre funcionários da própria empresa.

- Pesquisa e Desenvolvimento (de novos serviços, produtos e processos).

- Tecnologia de Informação.

- Auditoria (operacional e financeira).

. Credenciamento ISO.

- Benchmarking.

Entrevistou-se, em cada empresa, a pessoa indicada pela Direção como sendo 
o responsável direto pelo sistema de controle gerencial em uso, e os encarregados dos seguintes setores ou funções: Operações, Recursos Humanos , Marketing e Finanças.

\section{Empresas Selecionadas}

\section{Empresa A}

A empresa A é um hospital geral, com 120 leitos para internação; unidade de tratamento intensivo com 10 leitos; unidade de tratamento intensivo, neonatal e pediátrico; centro cirúrgico com 7 salas de operações, unidade de pacientes externos e unidade de emergência. Possui 40 especialidades, entre clínicas, cirúrgicas e pediátricas, e cerca de 950 funcionários, entre os quais, 250 médicos.

\section{Empresa B}

A empresa B atua na área de transporte de massa, por meio de concessão estatal para exploração deste tipo de serviço. Reúne atualmente cerca de 1.500 funcionários, 500 dos quais oriundos da antiga empresa estatal exploradora do serviço. A empresa também incorpora alguns funcionários de origem estrangeira, com grande experiência em operação de transporte metroviário em seu respectivo país . A empresa representa, portanto, um espaço para o convívio de pessoas oriundas de três ambientes culturais diversos, o privado, o estatal e aquele de outro país.

\section{Empresa C}

A empresa $C$ atua na área de prestação de serviços de engenharia submarina e possui, presentemente, cerca de 900 funcionários, distribuídos em cinco diretorias: Técnica (projetos), Operações, Construção Submarina, Comercial e Administrativa. Entre a presidência da empresa e o funcionário executivo, existe três camadas gerenciais: diretoria, superintendência e gerência.

Pertencente a um grupo estrangeiro, ela realiza, exclusivamente no Brasil, atividades focadas em cinco segmentos de mercado: construção submarina, survey (levantamentos geofísicos), embarcações de apoio (à construção e exploração), supply boats e militar. 
Tratamento dos Dados

\section{Tipologia das Empresas Selecionadas}

Utilizando as seis dimensões de processos de prestação de serviços de Silvestro et al. (apud Gianesi, 1994), verifica-se que a empresa A é uma loja de serviços, a empresa B é um serviço de massa enquanto a empresa $C$ é uma empresa de serviços profissionais.

\section{Objetivos de Desempenho Priorizados em cada Empresa}

Utilizando a metodologia prescrita por Gianesi (1994), e partindo dos depoimentos dos entrevistados, foram levantados os objetivos de desempenho priorizados por cada empresa selecionada. São eles:

. Empresa A : atendimento/competência (técnica)/tangíveis.

. Empresa B : consistência/tangíveis/velocidade de atendimento.

. Empresa C : acesso/competência (técnica)/flexibilidade.

\section{Quantificação dos Ativos/Recursos Intangíveis em cada Empresa}

Por meio do cruzamento e análise das várias respostas dos executivos às perguntas, muitas das quais comuns, procurou-se, inicialmente, descrever a situação dos ativos/recursos intangíveis encontrados em cada empresa. Para esta descrição, as respostas relacionadas aos fatores constituintes de cada tipo de ativo/ recurso intangível eram analisadas, basicamente, de forma qualitativa, a partir das realidades construídas por cada membro da empresa pesquisada.

Descritos os ativos/recursos intangíveis, instituiu-se um sistema de gradação dos fatores constituintes de cada um deles, de modo que se pudesse melhor visualizar a importância de cada ativo/recurso em cada empresa. Notar que a cada ativo/recurso intangível corresponde uma variável de pesquisa. As notas atribuídas a cada fator foram: 3 (bom), 2 (adequado) ou 1 (insuficiente).

A seguir pode ser visto, como exemplo, o processo de quantificação do ativo/ recurso Conhecimento Acadêmico e Tácito dos Funcionários. 


\section{Tabela 1: Ativo/Recurso - Conhecimento Acadêmico e Tácito dos Funcionários}

\begin{tabular}{|l|c|c|c|}
\hline \multicolumn{1}{|c|}{ Fator Constituinte do Ativo/Recurso Intangível } & Empresa A & Empresa B & Empresa C \\
\hline Valorização da experiência profissional. & 3 & 2 & 3 \\
\hline Mapeamento do conhecimento da empresa. & 3 & 2 & 3 \\
\hline Incentivos ao aumento do nível de escolaridade. & 2 & 2 & 3 \\
\hline Grau de parceria com instituições de ensino. & 1 & 1 & 3 \\
\hline Sistema de avaliação de satisfação dos funcionários. & 1 & 1 & 1 \\
\hline Trabalhos publicados por funcionários. & 1 & 1 & 2 \\
\hline Média das notas & 1,83 & 1,50 & 2,50 \\
\hline
\end{tabular}

\section{Relacionamento das Ações Gerenciais com Ativos/Recursos Intangíveis}

A seguir foram construídas matrizes, relacionando as ações gerenciais mais importantes, implementadas recentemente (1998-2000) nas empresas, com os ativos/recursos intangíveis. Nestas matrizes, e nas matrizes e tabelas que se seguem, as letras $\mathrm{C}, \mathrm{T}, \mathrm{R}$ e $\mathrm{P}$ se referem aos seguintes ativos/recursos intangíveis:

C - Conhecimento Acadêmico e Tácito dos Funcionários.

T - Processos Facilitadores de Transferência e Aquisição de Conhecimento.

R - Relacionamento com Clientes, Fornecedores e Mercado de Trabalho.

P - Capacitação em Pesquisa e Desenvolvimento.

Abaixo pode ser visto, como exemplo, a matriz de relacionamento, na empresa A, das ações gerenciais relevantes nos ativos/recursos intangíveis. 


\section{Empresa A}

\begin{tabular}{|c|c|c|c|c|}
\hline \multirow[t]{2}{*}{ AÇÃO GERENCIAL } & \multicolumn{4}{|c|}{$\begin{array}{c}\text { ATIVO/RECURSO } \\
\text { INTANGÍVEL }\end{array}$} \\
\hline & $\mathrm{C}$ & $\mathrm{T}$ & $\mathrm{R}$ & $\mathrm{P}$ \\
\hline 1. Manutenção da certificação ISO 9002. & & $\mathrm{X}$ & & \\
\hline $\begin{array}{l}\text { 2. Sistematização do processo de desenvolvimento } \\
\text { dos Recursos Humanos. }\end{array}$ & & $\mathrm{X}$ & & \\
\hline $\begin{array}{l}\text { 3. Implantação do processo de Avaliação dos Serviços } \\
\text { Ambulatoriais, utilizando as informações obtidas junto aos } \\
\text { clientes para definição de ações estratégicas. }\end{array}$ & & & $\mathrm{X}$ & \\
\hline $\begin{array}{l}\text { 4. Investimento em tecnologia (Modernização do Serviço de } \\
\text { Diagnóstico por Imagem, com introdução de novos } \\
\text { equipamentos e técnicas). }\end{array}$ & & $\mathrm{X}$ & & \\
\hline $\begin{array}{l}\text { 5. Implantação do Serviço de Medicina Nuclear } \\
\text { (o mais moderno no país). }\end{array}$ & & $\mathrm{X}$ & & \\
\hline $\begin{array}{l}\text { 6. Entrega imediata de resultados da maioria dos exames } \\
\text { realizados no hospital aos seus clientes. }\end{array}$ & & & $\mathrm{X}$ & \\
\hline $\begin{array}{l}\text { 7. Exigência de qualificação mínima (residência médica) para } \\
\text { admissão de médicos no Corpo Clínico do hospital. }\end{array}$ & $\mathrm{X}$ & & & \\
\hline $\begin{array}{l}\text { 8. Comunicação aos clientes do hospital de todos os serviços } \\
\text { disponíveis. }\end{array}$ & & & $\mathrm{X}$ & \\
\hline $\begin{array}{l}\text { 9. Comunicação aos clientes dos novos equipamentos e serviços } \\
\text { que o hospital começa a fornecer. }\end{array}$ & & & $\mathrm{X}$ & \\
\hline $\begin{array}{l}\text { 10. Controle anual da regularização dos médicos do Corpo } \\
\text { Clínico junto ao Conselho Regional de Medicina. }\end{array}$ & $\mathrm{X}$ & & & \\
\hline $\begin{array}{l}\text { 11. Certificação da Instituição em um Sistema de Qualidade, } \\
\text { baseado na NBR ISO } 9002 .\end{array}$ & & $\mathrm{X}$ & & \\
\hline $\begin{array}{l}\text { 12. Valorização do bom desempenho profissional, após } \\
\text { reestruturação dos processos de avaliação funcional e } \\
\text { recrutamento de pessoal. }\end{array}$ & $\mathrm{X}$ & & & \\
\hline $\begin{array}{l}\text { 13. Maior sistematização de treinamento interno e incentivo } \\
\text { aos treinamentos externos, como forma de manutenção das } \\
\text { capacidades e promover atualização. }\end{array}$ & & $\mathrm{X}$ & & \\
\hline $\begin{array}{l}\text { 14. Valorização das informações obtidas junto aos clientes } \\
\text { internos e externos (críticas e sugestões). }\end{array}$ & & & $\mathrm{X}$ & \\
\hline $\begin{array}{l}\text { 15. Padronização das normas e rotinas, bem como a contínua } \\
\text { revisão dos procedimentos. }\end{array}$ & & $\mathrm{X}$ & & \\
\hline Total de pares (ação gerencial X ativo/recurso). & 3 & 7 & 5 & 0 \\
\hline
\end{tabular}




\section{Relacionamento dos Índices e Indicadores com Ativos/ Recursos Intangíveis}

Finalmente, foram construídas matrizes, relacionando os indicadores e índices de desempenho, cuja evolução a Alta Direção de cada empresa acompanha com especial interesse, com os ativos/recursos intangíveis.

A seguir pode ser visto, como exemplo, a matriz de relacionamento, na empresa A, de seus índices e indicadores dos ativos/recursos intangíveis.

\section{Empresa A}

\begin{tabular}{|l|c|c|c|c|}
\hline \multicolumn{2}{|l|}{ INDICADORES E ÍNDICES DE DESEMPENHO } & \multicolumn{3}{|c|}{$\begin{array}{c}\text { ATIVO/RECURSO } \\
\text { INTANGIVEL }\end{array}$} \\
\cline { 2 - 5 } & $\mathrm{C}$ & $\mathrm{T}$ & $\mathrm{R}$ & $\mathrm{P}$ \\
\hline 1. Resultados relativos à satisfação dos clientes. & & & $\mathrm{X}$ & \\
\hline 2. Índice de Infecção Hospitalar. & & & & \\
\hline 3. Índice de Mortalidade. & & & & \\
\hline 4. Resultados de Auditorias da Qualidade. & & $\mathrm{X}$ & & \\
\hline 5. Taxa de Ocupação (utilização da capacidade instalada). & & & & \\
\hline 6. Índice de Infecção Hospitalar. & & & & \\
\hline 7. Freqüência de atrasos de médicos no ambulatório. & & & $\mathrm{X}$ & \\
\hline 8. Reclamações quanto ao atendimento no ambulatório. & & & $\mathrm{X}$ & \\
\hline 9. Reclamações quanto ao atendimento no Setor de Emergência. & & & $\mathrm{X}$ & \\
\hline 10. Número de cirurgias por especialidade. & & & & \\
\hline 11. Avaliação de Desempenho Profissional. & $\mathrm{X}$ & & & \\
\hline 12. Avaliação Pós-Treinamento. & $\mathrm{X}$ & & & \\
\hline 13. Avaliação dos Serviços Ambulatoriais e de Internação. & & & $\mathrm{X}$ & \\
\hline 14. Relatório Estatístico das Avaliações dos Serviços. & & & & \\
\hline 15. Índice de Turnover. & $\mathrm{X}$ & & & \\
\hline Total de pares (índice/indicador X ativo/recurso) & 3 & 1 & 5 & 0 \\
\hline
\end{tabular}


Análise dos Resultados

\section{Relacionamento de Ativos/Recursos Intangíveis com Objetivos de Desempenho das Empresas}

A empresa A tem dois de seus três objetivos prioritários de desempenho, relacionados diretamente a ativos/recursos intangíveis. Especificamente, o objetivo de desempenho atendimento (atmosfera) relaciona-se com o ativo/recurso intangível relacionamento com clientes, fornecedores e mercado de trabalho, enquanto o objetivo de desempenho competência se relaciona com o ativo/recurso intangível conhecimento acadêmico e tácito de seus funcionários.

A empresa B não possui nenhum de seus três objetivos prioritários de desempenho relacionados diretamente com ativos/recursos intangíveis.

Finalmente, a empresa C, além do objetivo prioritário de desempenho competência, associado, como na empresa A, com o ativo/recurso intangível conhecimento acadêmico e tácito de seus funcionários, também tem a flexibilidade como um objetivo prioritário associado ao ativo/recurso intangível relacionamento com clientes, fornecedores e mercado de trabalho.

Uma possível explicação para a inexistência de tais associações na empresa B é o fato de que ela é uma empresa do tipo serviço de massa, onde o relacionamento com clientes é tratado, tipicamente, de forma muito menos personalizada do que em outros tipos de empresas, e onde a ênfase é muito menor em pessoas (competências) do que em tecnologia (equipamentos). Neste tipo de empresa também se verifica pouca autonomia da força de trabalho, e quase nenhum contato com clientes, o que, em tese, produz pouco incentivo a relacionamentos.

\section{Importância dos Ativos/Recursos Intangíveis}

\begin{tabular}{|l|c|c|c|}
\hline & Empresa A & Empresa B & Empresa C \\
\hline Ativo/recurso intangível MAIS valorizado. & $\mathrm{T}(2,13)$ & $\mathrm{R}(2,00)$ & $\mathrm{C} / \mathrm{T}(2,50)$ \\
\hline $2^{\circ}$ ativo/recurso intangível MAIS valorizado. & $\mathrm{R}(1,89)$ & $\mathrm{T}(1,88)$ & \\
\hline $3^{\circ}$ ativo/recurso intangível MAIS valorizado. & $\mathrm{C}(1,83)$ & $\mathrm{C}(1,50)$ & $\mathrm{P}(2,29)$ \\
\hline Ativo/recurso intangível MENOS valorizado. & $\mathrm{P}(1,00)$ & $\mathrm{P}(1,29)$ & $\mathrm{R}(2,11)$ \\
\hline Valor médio. & $(1,71)$ & $(1,67)$ & $(2,35)$ \\
\hline
\end{tabular}

A constatação de que as empresas A e B, representantes típicas do setor de 
serviços, apresentam baixa capacitação em pesquisa e desenvolvimento, está plenamente conforme com o crônico baixo investimento em P\&D deste setor.

Em sintonia com o descrito no último parágrafo do item anterior, verifica-se o baixo valor $(1,50)$, encontrado na empresa $B$, para o ativo/recurso intangível conhecimento acadêmico e tácito de seus funcionários, o menor entre as três empresas. Discordando do último parágrafo, aparece um valor adequado $(2,00)$ para o ativo/recurso intangível relacionamento com clientes, fornecedores e mercado de trabalho. Provavelmente, isto se explica pelos recentes investimentos da empresa na área de marketing, procurando trazer mais calor humano para seus processos de prestação de serviços.

As médias das notas dos ativos/recursos intangíveis das empresas A e B estão aquém do valor julgado adequado (nota 2,00), nesta pesquisa, para cada ativo/ recurso.

\section{Ativos/Recursos Intangíveis Associados a Ações Gerenciais Relevantes}

\begin{tabular}{|l|c|c|c|}
\hline & Empresa A & Empresa B & Empresa C \\
\hline $\begin{array}{l}\text { Relação entre o número de associações } \\
\text { (ação gerencial relevante X ativo/recurso } \\
\text { intangível) encontradas e o número total } \\
\text { de associações possíveis. }\end{array}$ & $\begin{array}{c}0,25 \\
(15 / 60)\end{array}$ & $\begin{array}{c}0,18 \\
(10 / 56)\end{array}$ & $\begin{array}{c}0,17 \\
(12 / 72)\end{array}$ \\
\hline $\begin{array}{l}\text { Ativo/recurso intangível com MAIOR } \\
\text { número de associações. }\end{array}$ & $\mathrm{T}(7)$ & $\mathrm{R}(8)$ & $\mathrm{R}(6)$ \\
\hline $\begin{array}{l}\text { Ativo/recurso intangível com MENOR } \\
\text { número de associações. }\end{array}$ & $\mathrm{P}(0)$ & $\mathrm{P}(0)$ & $\mathrm{P}(0)$ \\
\hline $\begin{array}{l}\text { Número de ações gerenciais relevantes } \\
\text { encontradas em cada empresa e similares } \\
\text { às ações sugeridas por Sveiby (1997). }\end{array}$ & 8 & 7 & 9 \\
\hline
\end{tabular}

O valor médio das relações dos números de associações (ação gerencial relevante $\mathrm{X}$ ativo/recurso intangível) encontradas, em cada empresa, com o número total de associações possíveis, em cada empresa, é de 0,20 ((0,25 + 0,18 + 0,17)/3).

O ativo/recurso intangível relacionamento com clientes, fornecedores e mercado de trabalho aparece como o mais associado a ações gerenciais relevantes, enquanto o ativo capacitação em P\&D não está associado a nenhuma delas.

Observa-se, no caso da empresa B, que todas as suas sete ações gerenciais relevantes, similares às sugeridas por Sveiby (1997), foram direcionadas ao ati- 
vo/recurso intangível relacionamento com clientes, fornecedores e mercado de trabalho. Esta constatação está alinhada com o fato de ser este o ativo/ recurso intangível, para o qual foi encontrado, na tabela acima, o maior número de associações a ações gerenciais relevantes.

Com relação às ações gerenciais da empresa $\mathrm{C}$, similares às sugeridas por Sveiby (1997), nota-se que ela procura atuar com grande ênfase no ativo/recurso processos facilitadores de transferência e aquisição de conhecimento, investindo muito em sua estrutura organizacional interna. Este ativo/recurso intangível foi também o segundo, nesta empresa, em termos de número de associações a ações gerenciais relevantes.

Finalmente, verifica-se novamente uma completa ausência de ações gerenciais relevantes associadas ao ativo/recurso intangível capacitação em P\&D.

\section{Ativos/Recursos Intangíveis Associados aos Indicadores e Índices de Desempenho Relevantes}

\begin{tabular}{|l|c|c|c|}
\hline & Empresa A & Empresa B & Empresa C \\
\hline $\begin{array}{l}\text { Relação entre o número de associações } \\
\text { (indicador/índice X ativo/recurso }\end{array}$ & $\begin{array}{c}0,15 \\
(9 / 60)\end{array}$ & $\begin{array}{c}0,14 \\
(9 / 64)\end{array}$ & $\begin{array}{c}0,11 \\
(9 / 80)\end{array}$ \\
$\begin{array}{l}\text { intangível) encontradas e o número total } \\
\text { de associações possíveis. }\end{array}$ & $\mathrm{R}(5)$ & $\mathrm{R}(8)$ & $\mathrm{T}(5)$ \\
\hline $\begin{array}{l}\text { Ativo/recurso intangível com MAIOR } \\
\text { número de associações. }\end{array}$ & $\mathrm{P}(0)$ & $\mathrm{P}(0)$ & $\mathrm{P}(0)$ \\
\hline $\begin{array}{l}\text { Ativo/recurso intangível com MENOR } \\
\text { número de associações. }\end{array}$ & 7 & 7 & 2 \\
\hline $\begin{array}{l}\text { Número de indicadores/índices relevantes, } \\
\text { encontrados em cada empresa, e similares } \\
\text { aos sugeridos por Sveiby (1997). }\end{array}$ & & & \\
\hline
\end{tabular}

O valor médio das relações dos números de associações (indicador/índice relevante $\mathrm{X}$ ativo/recurso intangível) encontradas, em cada empresa, com o número total de associações possíveis, em cada empresa, é de 0,13 ((0,15 + 0,14 + 0,11)/3).

O ativo/recurso intangível relacionamento com clientes, fornecedores e mercado de trabalho aparece como o mais associado aos indicadores e índices de desempenho relevantes, enquanto o ativo capacitação em $\mathbf{P} \& \mathbf{D}$ não está associado a nenhum deles.

Com relação aos indicadores e índices de desempenho, similares aos sugeridos por Sveiby (1997), nota-se que, em todas as empresas, eles estão relacionados, 
primordialmente, com o ativo/recurso intangível relacionamento com clientes, fornecedores e mercado de trabalho. Esta constatação está alinhada com o fato de ser este o ativo/recurso intangível, para o qual se encontrou para as empresas A e B, na tabela acima, o maior número de associações a indicadores e índices de desempenho.

\section{Análise Agregada dos Dados}

Se considerarmos o conjunto das três empresas, encontraremos os resultados abaixo.

\begin{tabular}{|l|c|c|c|c|}
\hline & $\mathrm{C}$ & $\mathrm{T}$ & $\mathrm{R}$ & $\mathrm{P}$ \\
\hline Nota de cada ativo/recurso intangível. & 1,94 & 2,17 & 2,00 & 1,53 \\
\hline $\begin{array}{l}\text { Soma das associações (ação gerencial X ativo e/ou } \\
\text { recurso intangível) verificadas. }\end{array}$ & 4 & 14 & 19 & 0 \\
\hline $\begin{array}{l}\text { Soma das associações (indicador/índice X ativo } \\
\text { e/ou recurso intangível) verificadas. }\end{array}$ & 5 & 6 & 16 & 0 \\
\hline
\end{tabular}

\section{Perfil dos Dispêndios Associados a Ativos/Recursos Intangíveis}

Na empresa A, o maior dispêndio ocorreu no item tecnologia de informação, enquanto na empresa $\mathrm{B}$ tal fato se deu no item publicidade. Esta empresa, comparativamente às outras, realizou também gastos acentuados com eventos de socialização. Já na empresa C, o maior dispêndio foi verificado no item treinamento. Comparativamente às demais empresas, seu dispêndio em auditoria (operacional e financeira) também foi elevado.

As ausências de dispêndios em pesquisa de opinião podem ser explicadas, na empresa A, pela ausência da função marketing e, na empresa C, pelo fato de esta empresa atuar, basicamente, nos mercados industrial e governamental. $\mathrm{Na}$ empresa B, somente a partir do ano 2000 foi contratada empresa especializada para realizar tais pesquisas, duas vezes ao ano.

A grande e notável ausência de dispêndios, em todas as empresas, verificou-se no item pesquisa e desenvolvimento (de novos serviços, produtos e processos). 


\section{Conclusão}

Da análise efetuada, podem ser tiradas algumas conclusões, que passam a ser listadas a seguir.

- Apesar da carência de parâmetros que possam ser utilizados em comparações, o valor médio $(0,20)$ das relações do número de associações (ação gerencial relevante $\mathrm{X}$ ativo/recurso intangível) encontradas com o número total de associações possíveis, em cada empresa, parece indicar pouca orientação para ações gerenciais relevantes em ativos/recursos intangíveis.

. Igualmente, o valor médio $(0,13)$ das relações do número de associações (índice/indicador importante $\mathrm{X}$ ativo/recurso intangível) encontradas com o número total de associações possíveis, em cada empresa, parece apontar a baixa importância, concedida pelas empresas, ao sistema de medição de ativos/recursos intangíveis.

. Da análise agregada dos dados, verifica-se que os ativos/recursos intangíveis processos facilitadores de transferência e aquisição de conhecimento e relacionamento com clientes, fornecedores e mercado de trabalho são os ativos/recursos mais associados tanto a ações gerenciais relevantes, quanto a indicadores/índices importantes. São eles também aqueles que receberam as maiores notas. Exatamente o oposto acontece com o ativo/recurso capacitação em P\&D que, além de ter recebido a menor nota, não foi associado a nenhuma ação gerencial nem a indicador/índice de desempenho.

- Parece haver relação entre o tipo da empresa de serviços (e seus objetivos de desempenho) e os ativos/recursos intangíveis mais valorizados por elas; senão, vejamos a empresa $\mathrm{C}$, do tipo serviços profissionais, dotada de uma estrutura organizacional tipo projeto (divisão dos funcionários em equipes alocadas em empreendimentos): ela valoriza a competência técnica de seus funcionários e procura facilitar, entre eles próprios e com clientes selecionados, oportunidades de trocas de conhecimento. A empresa A, uma loja de serviços, com um número de clientes muito maior do que a empresa $\mathrm{C}$, procura valorizar o relacionamento entre seus funcionários e os clientes. Com relação à empresa B, uma empresa tipo serviços de massa, onde os serviços são usualmente padronizados e há pouco contato com os clientes, parece estranho que ela tenha exatamente o ativo/recurso relacionamento como aquele de maior importância. Entretanto tal fato pode ser explicado pela recente reorganização interna pela qual passou, com mudança de controle proprietário e com profundas modificações nos perfis de seus funcionários. Tais fatos geraram a neces- 
sidade de investimentos em eventos de socialização entre funcionários, e em eventos formadores de nova imagem da empresa junto aos clientes.

. Na presente arena de competição, em que as empresas competem com competidores nacionais e internacionais (globalização), parece que esforços para melhoria dos ativos/recursos intangíveis conhecimento acadêmico e tácito de seus funcionários e capacitação em P\&D, estão sendo necessários nas empresas A e B; portanto ações gerenciais relevantes, monitoradas por indicadores/índices de desempenho que sejam consultados com freqüência, devem ser implementadas.

Para esta finalidade, Kaplan e Norton (1992, 1993), Edvinsson e Malone (1997) e Sveiby (1997) oferecem uma extensa relação de possíveis ações gerenciais e índices/ indicadores de desempenho, relacionados com ativos/recursos intangíveis.

\section{RefERÊnCIAS Bibliográficas}

ANTHONY, R. N.;

GOVINDARAJAN, V.

Management control systems.

9. ed. Boston: Irwin/MacGrawHill, 1998.

ANTUNES, M. T. P.

Capital intelectual. São Paulo: Atlas, 2000.

EDVINSSON, L.;

MALONE, M. S.

Intellectual capital. New York: HarperCollins Publishers, 1997.

\section{FLAMHOLTZ, E.}

Effective organizational control: a framework, applications and implications.

European

Management Journal, v. 14, n. 6, p. 596-611, Dec. 1996.
GIANESI, I. G. N.;

CORRÊA L. C.

Administração estratégica de serviços. São Paulo: Atlas, 1996.

GOMES, J. S.

Um estudo exploratório sobre controle gerencial em empresas estatais brasileiras. Rio de Janeiro, 1983. Tese (Doutorado em Administração) - Instituto de Pós-Graduação e Pesquisa em Administração, Universidade Federal do Rio de Janeiro.

Contabilidade para MBAs: textos e casos. Rio de Janeiro: Campus, 2000. 
GRANT, R. M.

Toward a knowledge-based theory of the firm. Strategic Management Journal, v. 17, p. 109-122, Dec. 1996. Special issue.

HOFSTEDE, G.

Cultura e organizações: compreender a nossa programação mental. Lisboa: Sílabo, 1997.

JOHANSON U.

Mobilizing change: characteristics of intangibles proposed by eleven Swedish firms. In: MEASURING AND $\begin{array}{lllllllll}R & E & P & O & R & T & I & N & G\end{array}$ INTELLECTUAL CAPITAL: EXPERIENCE, ISSUES AND

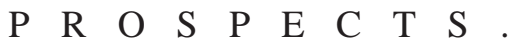
I N T E R N A T I O N A L SYMPOSIUM, 1999, Amsterdam. Proceedings... Amsterdam: [s.n.], 1999.

JOHANSON U.;

MARTENSSON M.;

SKOOG M.

Measuring and managing intangibles: eleven Swedish qualitative exploratory case studies. In: MEASURING AND $\begin{array}{lllllllll}R & E & P & O & R & T & I & N & G\end{array}$ INTELLECTUAL CAPITAL: EXPERIENCE, ISSUES AND

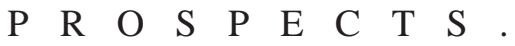
I N T E R N A T I O N A L SYMPOSIUM, 1999, Amsterdam. Proceedings... Amsterdam: [s.n.], 1999.
KAPLAN R. S.;

NORTON D. P.

The balanced scorecard measures that drive performance. Harvard Business Review, Jan./Feb. 1992.

Putting the balanced scorecard to work. Harvard Business Review, Sept./Oct. 1993.

LEONARD, D.; SENSIPER S.

The role of tacit knowledge in group innovation. California Management Review, v. 40, issue 3, p. 112-132, Spring 1998.

LOVDAL H.

Norway: competence capital. In: MEASURING AND $\begin{array}{lllllllll}R & E & P & O & R & T & I & N & G\end{array}$ INTELLECTUAL CAPITAL: EXPERIENCE, ISSUES AND $\begin{array}{llllllllllllll}P & R & O & S & P & E & C & T & S\end{array}$. I N T E R N A T I O N A L SYMPOSIUM, 1999, Amsterdam. Proceedings... Amsterdam: [s.n.], 1999.

LUSCH R. F.;

HARVEY M. G.

The case for an off-balance-sheet controller. Sloan Management Review, p. 101-105, Winter 1994.

LYNN, G. S.

New product team learning: developing and profiting from your knowledge capital. California Management Review, v. 40, issue 4, p. 74-93, Summer 1998. 
MALONE, M. S.

New metrics for a new age. Forbes ASAP, p. 40-41, Apr. 1997.

\section{MASCITELLI, R.}

From experience: harnessing tacit knowledge to achieve breakthrough innovation. Journal of Product Innovation Management, v. 17, issue 3, p. 179, May 2000.

\section{MONTEIRO, D. R.}

A contabilidade de recursos humanos: uma exposição de suas técnicas e uma visão crítica de suas perspectivas. Rio de Janeiro, 1980. Dissertação (Mestrado em Administração) - Instituto de Pós-Graduação e Pesquisa em Administração, Universidade Federal do Rio de Janeiro.

\section{MOURITSEN J.}

Driving growth: economic value added versus intellectual capital. Management Accounting Research, p. 461-482, issue 9, 1998.

NONAKA, I.;

TAKEUCHI, $\mathrm{H}$.

The knowledge-creating company. New York: Oxford University Press, 1995.
ROBERTS H. J. E.

Management accounting and control systems in the knowledgeintensive firm. In: ANNUAL CONGRESS OF THE EUROPEAN ACCOUNTING ASSOCIATION, 21., 1998, [S.I.]. Proceedings... [S.l.: s.n.], 1998.

The control of intangibles in the knowledge-intensive firm. In: ANNUAL CONGRESS OF THE EUROPEAN A $C$ C $C$ O ASSOCIATION, 22., 1999, Bordeaux. Proceedings... Bordeaux: [s.n.], 1999.

SPENDER, J. C.

Making knowledge the basis of a dynamical theory of the firm. Strategic Management Journal Special Issue, v. 17, p. 45-62, Dec. 1996.

SVEIBY, K. E.

The new organizational wealth. San Francisco: Berrett-Koehler Publishers, 1997.

TSOUKAS, $\mathrm{H}$.

The firm as a distributed knowledge system: a constructionist approach. Strategic Management Journal, v. 17, p. 11-25, Dec. 1996. Special issue. 